\title{
LA PRECISIÓN CONCEPTUAL Y TERMINOLÓGICA EN EL ÁMBITO POLICIAL Y JUDICIAL: TRADUCCIÓN Y TRANSCRIPCIÓN DE ESCUCHAS TELEFÓNICAS \\ Mobamed El-Madkouri Maataoui \\ Universidad Autónoma de Madrid
}

\begin{abstract}
The objective of this research is to analyze a communicative activity of enormous legal and judicial importance, namely, interpretation and translation in judicial processes. More specifically, the aim is to see the framework of performance of the police interpreter and analyze the interpretive processes of telephone interceptions. This activity, for which unskilled personnel are very often hired, requires a series of skills and aptitudes that transcend any other type of regular and regulated interpretation. The corpus consists of the introspection of the researcher himself as interpreter and former coordinator of a team of interpreters in Social Services, as well as results of an open survey to other interpreters of this modality.
\end{abstract}

KEYWORDS: telephone interceptions, court interpreting, community interpreting.

\section{RESUMEN:}

El objetivo de esta investigación es abordar una actividad comunicativa de enorme trascendencia jurídica y judicial, la interpretación y traducción en los procesos judiciales. Se trata específicamente de dar cuenta del marco de actuación del intérprete policial y analizar los procesos interpretativos de las interceptaciones telefónicas.

Esta actividad, por la cual se contrata muy a menudo a personal no cualificado, necesita de una serie de destrezas y aptitudes que trascienden cualquier otro tipo de interpretación regular y reglada. El corpus manejado consiste en la introspección del propio investigador como intérprete y ex coordinador de un equipo de intérpretes en los Servicios Sociales, así como en la encuesta abierta a otros intérpretes de esta modalidad.

PALABRAS CLAVE: interceptaciones telefónicas, interpretación judicial, interpretación en los servicios públicos.

Fecha de recepción: 10/01/2017

Fecha de revisión: 05/03/2017

Fecha de aceptación: 20/09/2017

Páginas: $119-128$ 


\section{INTRODUCCIÓN}

El objetivo del presente artículo es dar cuenta de las confluencias entre los distintos saberes del intérprete-traductor y del perito en el ámbito judicial. Se intentará explorar un campo, el de la interpretación de las escuchas telefónicas, poco conocido y explorado en el ámbito universitario, pero muy presente y debidamente regulado en los ámbitos de la Seguridad y de la Justicia.

Con relación a las conversaciones que se producen en otros idiomas distintos a las lenguas oficiales españolas, se requerirá de un intérprete, quien no tiene que ser un traductor oficial, pero sí alguien que conozca el idioma plenamente (Art. 231 LOPJ). Puede ser miembro de la Policía, o alguna persona particular que sea de su confianza, puesto que lo que es esencial es el conocimiento material del idioma por parte del perito y que la lengua extranjera no sea una barrera que dificulte la labor de la Policía en esa vigilancia auditiva que se realiza a través delas intervenciones telefónicas, ni una disculpa para abstraerse del control efectivo total sobre los resultados obtenidos. (CasabiancaZuleta, 215: 248)

La finalidad será, por tanto, definir el concepto de transcripción y traducción en los autos judiciales, Determinar el alcance legal y judicial del léxico en el ámbito de la prevención y persecución de la delincuencia organizada y, finalmente, determinar los rasgos distintivos del léxico específico de algunos sociolectos y su alcance pragmático judicial.

El corpus manejado como objeto de análisis se divide entre tres categorías: material real manejado por el investigador como consecuencia de su desempeño como intérprete jurado, entrevistas con traductores e intérpretes especialistas en este ámbito de interpretación, y finalmente observación de material revisado e informado para ser presentado a la justicia, a cargo de la defensa de unos imputados.

\section{CONCEPTO DE TRANSCRIPCIÓN Y TRADUCCIÓN DE ESCUCHAS TELEFÓNICAS, EN LOS AUTOS JUDICIALES}

Las Fuerzas de Seguridad del Estado, además de las labores convencionales e intuitivas que el ciudadano de a pie les atribuyen, viendo su actuación en las calles, sus exhibiciones en las fiestas y ferias y su visualización y visibilizarían en el cine, es una reproducción en miniatura de prácticamente todas profesiones civiles. Sus especialidades van desde la fontanería o mecánica hasta el análisis de las partículas. Su agentes no solo son los portadores de armas, sino también de titulación universitaria y de conocimientos técnicos y científicos universitarios. En la policía hay ingenieros, pilotos, juristas, químicos, biólogos, lingüistas, traductores, etc. De todos ellos interesan en este trabajo las últimas dos profesiones, la lingǘstica y la traductora, por relacionarse estrechamente con el objetivo de la presente investigación: las escuchas telefónicas, su transcripción y traducción.

\subsection{LA ESCUCHA TELEFÓNICA EN EL ÁMBITO DE LA SEGURIDAD}

Una las misionesde las Fuerzas de Seguridad del Estado, tal y como las conciben los ciudadanos, es hacer un seguimiento en tiempo real de todo lo que pueda suponer una amenaza a su seguridad o que infrinja la ley comúnmente convencionalizada por los representantes del pueblo español. Esto es, velar a que la situación social y comunitaria esté libre de amenazas y riesgos. La responsabilidad de mantener la seguridad, independientemente de su tipo, recae, por ello, sobre el Estado, los gobiernos e, incluso,sobre los individuos, cada cual según su responsabilidad y competencias atribuidas legalmente.Igualmente, el sistema judicial, como garante de la justicia ciudadana y la equidad para todas las partes que viven en el territorio español y en su jurisdicción judicial, vela por que todas las actuaciones de la policía judicial sea conforme a ley, en consonancia con lo que establece, en términos generales, el preámbulo de la Ley 36/2015, de 28 de septiembre, que entiende la seguridad como: 
«La acción del Estado dirigida a proteger la libertad y el bienestar de sus ciudadanos, a garantizar la defensa de España y sus principios y valores constitucionales, así como a contribuir junto a nuestros socios y aliados a la seguridad internacional en el cumplimiento de los compromisos asumidos».

Por ello, visto el sistema constitucional y de garantías del Estado, los agentes e implicados en los seguimientos y en la información, están llamados en todo tiempo a una precisión, meticulosidad y rigor en la reunión de las pruebas, su disposición y su presentación.

Cabe preguntarse, visto lo anterior, si desde ya el inicio de una operación de seguimiento, la policía judicial española tiene derecho realizar seguimientos telefónicos a los ciudadanos o a personas residentes en territorio español, la respuesta es negativa aunque con algunas salvedades "marginales" como señala Ron Romero (2011). Por lo que, se garantiza, en principio, el control judicial sobre el procesode escuchas y seguimiento realizados en territorio español por agentes españoles.

A efectos de esta investigación, de todas las grabaciones que la policía pueda realizar, interesan precisamente las escuchas telefónicas. Son grabaciones que implican al intérprete-traductor, realizadas sobre comunicaciones entre individuos y pueden ser de dos tipos:

\subsubsection{Escuchas en vivo}

En este caso, el intérprete suele seguir la comunicación en tiempo real, esto es en vivo. Aun así, existe en principio, un soporte físico, grabado, de la comunicación que este mismo intérprete, u otro, interpreta y transcribe para que sea presentado como prueba acusatoria ante el juez. La producción de la traducción de una escucha en vivo suele realizarse desde una perspectiva pragmática y funcional, menos complicada que si fuera una grabación en diferido. En las escuchas en vivo, el intérprete suele disponer de más elementos contextuales y pragmáticos que le ayudan a captar las palabras exactas y el modo de interpretarlas. Las interferencias en vivo son reconocibles como tales porque el intérprete sabe si los perseguidos están en un coche, en un domicilio, comiendo, en la calle... y más datos que le proporcionan los agentes policiales, mientras que en diferido, se le entrega un audio cuyos protagonistas son difíciles de localizar en el espacio y en el tiempo, llegando a veces a saber establecer el turno real de las intervenciones en la conversación grabada.

\subsubsection{Escuchas en diferido}

Las escuchas telefónicas en diferido suelen ser grabaciones que la policía presenta al intérprete. En este caso, éste dependerá casi exclusivamente de la buena voluntad colaboradora y de la confianza del agente policial para proporcionarle datos extralingüísticos que le ayuden a contextualizar la escucha, su transcripción, su interpretación y, finalmente, su producción traductora.

Tanto las escuchas en vivo como las en diferido, realizadas por las Fuerzas de Seguridad y que implican el intérprete, incluyen: el narcotráfico, la inmigración ilegal, el tráfico de armas, el blanqueo de dinero, el terrorismo, el espionaje, etc. Existen otro tipo de grabaciones privadas, como las realizadas por detectives privados, que pueden versar sobre prácticamente todos los ámbitos de la vida: relación de pareja, paternidad, desavenencias familiares, relaciones laborales, coacciones y chantajes,...

\subsection{LA COLABORACIÓN ENTRE EL AGENTE DE LA POLICÍA JUDICIAL Y EL INTÉRPRETE}

Cabe destacar que el intérprete de la Policía es generalmente percibido como ajeno al Servicio, y lo es. El intérprete, por lo general,no es miembro del grupo de la policía judicial. Suele ser un profesional contratado directamente o proporcionado a la policía por alguna empresa de traducción einterpretación. 
La precisión conceptual y terminológica en el ámbito policial y judicial: traducción y transcripción ...

En ese sentido, se entiende que el agente "de la casa" recele de una persona "ajena" al servicio. Esta desconfianza, muy común, llega a veces a minar la relación entre estos dos profesionales.

\subsubsection{La confidencialidad y la traducción policial.}

Este tipo de desconfianza no afecta solo a posibles recelos por hipotéticos riesgos de revelar secretos de la investigación llevada acabo, sino que cuestiona a veces la labor interpretativa. Preguntas recelosas del tipo "¿es verdad que dice esto?" son muy frecuentes. Otras manifestaciones de este recelo ante la labor del intérprete, aunque legítimas, como someter abiertamente el mismo fragmento a varios profesionales, incomodan alprimero porque recibe la impresión de que están cuestionandomanifiestamente su labor por cuanto hacen dudar de su criterio.

Es muy común igualmente ver que el que maneja el teclado del ordenador no sea el mismo intérprete, sino el policía. En este caso, se da otro tipo de cuestiones que debe pensarse y solucionarse. Los intérpretes profesionales al servicio de la Policía Judicial se quejan muy a menudo de observar que su traducción "aparece plagado de errores ortográficos"que algunos agentes son reaciosa admitir y corregir. Se entiende que una vez en manos del juez, la traducción y su redacción se entienden como responsabilidad exclusiva del intérprete que la suscribe. De ello da fe este fragmento:

La fiscal del caso, Olga Sánchez, no ha ocultado su enfado cuando se ha dirigido a los intérpretes y les ha interrogado sobre su método de trabajo. Cuando uno de los intérpretes dice que "ellos (los italianos) caen en interpretaciones que no son adecuadas", la fiscal les ha espetado elevando el tono de voz: "¿Y la suya es la adecuada en un contexto de terrorismo?" "¿Cuántas veces lo han oído?", ha interrogado la fiscal. "Concretamente, uno de los pasajes conflictivos, 20 veces", ha respondido el intérprete.

Olga Sánchez también les ha preguntado si habían limpiado el ruido de fondo que a veces impide oír bien las conversaciones. Ellos han respondido que no. Y ella les ha reprochado que los traductores de la Policía italiana sí lo hicieron.

Entonces, el intérprete ha respondido que ellos nunca llenan o interpretan "lagunas" que no se oyen, sino que sólo han traducido lo que se escucha bien. "Siempre partimos de unidades que hemos definido de manera muy segura", ha alegado'.

Esta noticia revela que en los juicios la figura del policía, en lo referente a la interpretación propiamente dicha, desaparece. El intérprete tiene la obligación de contestar, a solas, a todas y cada una de las preguntas y personas implicadas en el juicio, que el juez autorice. El desarrollo de una independencia cognitiva positiva es importante en este ámbito.

Se dan casos reales, en las dependencias policiales, de polémica sobre la interpretación yinterpretabilidad de algunos fragmentos. Es común que el intérprete diga "esto significa X", a lo cual el policía replica preguntando si tal fragmento "podría significar también y". Si el intérprete es principiante en estas lides contesta que "podría", lo que aparecerá en la transcripción sería el caso y no el real. A veces el grupo policial ya está completamente convencido de la culpabilidad del "pinchado" y quiere cerrar el caso cuanto antes aunque en detrimento de la precisión y rigor de la interpretación y transcripción. Son casos marginales, pero existen.

\subsection{2. ¿Es traditore el traduttore?}

El intérprete junto con el policía maneja un material altamente sensible y transcendental. Sin embargo, el intérprete en estas actuaciones está supeditado a la confianza del policía.Esta supeditación del intérprete es consecuencia de la superioridad conferida legalmente al policía judicial ya que éste puede elegir para intérprete a cualquier persona de "su confianza". Existen, además, más razones para

${ }^{1}$ https://www.elmundo.es/elmundo/2007/05/30/espana/1180539942.html (16 de mayo de 2019) 
esta representación inferior de la figura del intérprete policial y judicial en tanto que intérprete en los Servicios Públicos. Hale (2010: 25) afirma que «el estatus de los participantes en las situaciones comunicativas influencia el estatus del intérprete. Puesto que los intérpretes de conferencias interpretan para figuras internacionales su propia categoría se eleva». Es decir, que el estatuto del intérprete viene determinado por el estatuto de la persona a quién intérprete. Todo ello hace que se piense que el agentepolicial sea considerado, en estos casos concretos, fiable y de confianza; mientras que el intérprete es al revés.

Cabe destacar igualmente que a veces la sospecha policial sobre la profesionalidad y fiabilidad de sus intérpretes o de los que están a su servicio, es fundada. Primero, la remuneración del intérprete policial deja mucho que desear. Segundo, el servicio de los intérpretes policiales es externado. Esto quiere decir, que son empresas ajenas a la policía las que prestan el servicio de la interpretación policial. Éstas, visto los precios pagados y la falta de personal cualificado para todaslas lenguas demandadas, se contentan con bachilleres o con personas sin ninguna formación en traducción e interpretación o en filología. Se dan casos de tenderos, sin estudios, que han asumido la interpretación para la policía o para los juzgados.

Vistos los elevados costes que supone la contratación de graduados en traducción interpretación o de la formación continua de los intérpretes ya en plantilla, la situación no tiene vistas de resolverse amedio plazo. El perfil de estos intérpretes oscila entre personas sin formación, bachilleres, diplomados en turismo, licenciados en filología española, graduados en economía, etc. Estos diplomados y graduados suelen concebir su paso por la interpretación policial como un sucedáneo al paro. En cuanto encuentran posibilidad tengo otro trabajo mejor remunerado, Aunque no tenga nada que ver con la interpretación, abandonan la interpretación pasa ahora dejando lo recogerás mañana y traducción policial.

De todos modos y cualquiera que sea la condición del intérprete, la veracidad y la calidad de lo que interpreta, transcribe y traduce es, jurídica y judicialmente, es exclusivamente suya. La única jerarquía además de la mera organización administrativa y de organización del trabajo que el intérprete ha de acatar es la procedente de la legalidad y del imperio de la ley.

Este intérprete se considerará como un perito, y como tal podrá ser llamado por alguna de las partes con el fin de auxiliar al tribunal a apreciar el alcance de las conversaciones (Casabianca Zuleta, 2015: 248)

El intérprete no compite por medallas blancas, ni rojas, sino que su cometido es acometer la misión que se le incumbe legalmente con responsabilidad, rigor, ética y equidad, centrándose en identificar lo dicho, determinar lo que se quiere decir y construir un discurso traducido acorde al escopo de la traducción. Ello es posible mediante la confianza de uno en sí mismo y en su saber hacer; lo cual es muy fácil de conseguir mediante una buena formación traductora, un conocimiento enciclopédico de las leyes y del funcionamiento del mundo de la delincuencia. Para el último elemento extralingǘ́stico, la colaboraciónreglamenta del agente policial sería fundamental. Si éste proporciona al intérprete los datos extralingüísticos necesarios para la contextualización pragmática para la correcta interpretación de lo dicho.

\section{ASPECTOS LINGÜÍSTICOS Y EXTRALINGÜÍSTICAS DE LA INTERPRETACIÓN EN EL ÁMBITO JUDICIAL}

El ámbito de la interpretación policial y judicial es un campo de estudio relativamente nuevo. Aunque son ya numerosos los trabajos monográficos sobre esta subespecialidad de la Traducción e Interpretación en los Servicios Públicos llevadas a cabo principalmente en la UAH y la URJC, las investigaciones que manejen datos concretos y corpus reales son escasísimas. Este material es altamente sensible por lo que consultarlo necesita una serie de autorizaciones que ningún rango policial se atrevería a conceder. Sacarlo fuera de las dependencias policiales y a la luz del día es tarea imposible. En vista de ello,la investigación en estos ámbitos se realiza, cuando maneja datos, por investigadores-traductores e 
La precisión conceptual y terminológica en el ámbito policial y judicial: traducción y transcripción ...

intérpretes que los han manejado. Por ello, las dinámicas del trabajo policial y judicial, las jerarquías, el ámbito de trabajo, la formación del intérprete y su confianza en sí mismo, entre otros factores, son circunstancias que deben tenerse en cuentapara una interpretación y traducción de esta naturaleza para evaluar el resultado final del trabajo del intérprete policial y judicial.

Sin embargo, lo que más determina las construcciones lingüísticas del intérprete policial y judicial, además de las condiciones en que desarrolla su trabajo, la especificidad del léxico, los fraseologismos propios del género textual y las metáforas,... es el uso específico y semiótica que se hace de la lengua convencional en el ámbito de la delincuencia, como por ejemplo:

- "Quand tu files le pain rond, attends où l'homme à la guitare"

- "Cuando pases el pan redondo, espera donde el hombre de la guitarra"

Se trata de un fragmento de la interceptación de una conversación entre al menos dos individuos en sendos coches, perseguidos disimuladamente por agentes de la Policía Nacional española. Los agentes no entendieron nada, ni el intérprete que lo tradujo tampoco. Fue cuando reaccionó ¿¿ué es lo que podría haber en la carretera que se parezca a un pan redondo y si hay algún músico o algo que se la parezca por la zona?

Pues el pan redondo no es otra cosa que una rotonda de cambio de sentido y el hombre de la guitarra es el "Tío Pepe" y el "toro" que jalonan las autovías y carreteras española como monumentos nacionales.

\section{EL ALCANCE LEGAL Y JUDICIAL DEL LÉXICO}

La interpretación de lasinterceptaciones auditivas y audiovisuales, especialmente las telefónicas, es de capital importancia para la prevención del crimen organizado de tipo sanitario, económico o contra la seguridad ciudadana. El control se realiza muy amenudo en tiempo real, por lo que el intérprete está constantemente conectado y cableado a los aparatos como si fuera un periférico más. Por ello, las horas de espera, como si fuera un cazador, y la atención despegada en ello hacen de este trabajo una intensa y agotadora labor por cuanto no sólo hay que prestar atención para escuchar atentamente, sino para poder entender un lenguaje particularizado en el cual los hablantes intentan dificultar la comprensión y enmascarar sobremanera el querer decir de sus construcciones lingüísticas.

La actuación del intérprete, en el ámbito policial, no queda en los ordenadores de las dependencias policiales, a no ser que la causa no tuviera alcances judiciales, sino que sustranscripciones acaban en manos del juez de instrucción, de la fiscalía y del juez encargado de dilucidar la causa y juzgar en consecuencia, como se ha visto anteriormente. Por ello, el poder del intérprete es tan crucial que llega a meter a inocentes en la cárcel o a dejar a delincuentes en la calle, tal y como podemos leer en una noticia publicada por El Mundo el 30/5/2007 con el título de: Los intérpretes del 11-M creen errónea la traducción que incrimina a 'El Egipcio'2

\subsection{NATURALEZA DE LAS TRANSCRIPCIONES EN EL ÁMBITO DE LA TRADUCCIÓN POLICIAL}

Cuando se habla de la transcripción en el ámbito de la interpretación en el ámbito policial, lo que realmente se quiere decir es la transcripción de la interpretación.Es decir, del texto en español de lo que el intérprete ha oído en otra lengua. En ningún momento aparece la transcripción de la lengua de partida, original, que haya dado lugar ala traducción. Ésta queda grabada y debidamente custodiada por el equipo policial denunciante. De hecho, la Sentencia 9/2011 del Tribunal Constitucional dejo zanjada la polémica sobre si debe adjuntarse la transcripción de la lengua original, en este caso rumano. A juicio del tribunal juzgante el control judicial sobre la escucha telefónica alcanza también a la lengua original (escuchada 
con asistencia de un intérprete) y al suporte de la misma, por lo que no es preceptivo adjuntar su transcripción a los autos.

Por ello, cuando se trata de desacuerdos sobre la interpretación de algún fragmento o su traducción, el segundo intérprete o perito, con mandato judicial, vuelve directamente al material auditivo.

En algunos casos el texto español de la transcripción hace una diferencia explícita entre la traducción "lo que realmente se ha dicho" y la interpretación o explicación del equipo investigador de "lo que realmente se quiere decir". Este proceder diferencia "lo dicho" como explicatura de su implicatura, y por tanto de su explicación, comentario y valoración. Esto garantiza en cierto el rigor y la fiabilidad de la traducción.

\subsection{EL ALCANCE LEGAL Y JUDICIAL DEL LÉXICO EN EL ÁMBITO DE LA TRADUCCIÓN DE LAS ESCUCHAS}

A efectos judiciales, cada palabra, cada expresión, cada fraseologismo tiene un peso que el intérprete o traductor podría ignorar. Es muy común oír el siguiente mandato del juez al traductor "haga Vd. una traducción lo más literal posible" o que la policía haga en su "Acta de transcripción" la siguiente mención: "A partir de este momento se realiza transcripción literal".

Aquí la literalidad no tiene la misma acepción denostada por profesores de traducción e interpretación en las aulas de la Universidad. La literalidad, en cuestión, implica la preocupación porque se refleje en la traducción no solo lo que una determinada persona ha dicho, sino cómo lo ha dicho. La "manera de hablar de una persona", su idiolecto, es muy a menudo determinante del curso de la acusación. Un ejemplo de ello, sacado de un juicio seguido en la Audiencia provincial de San Sebastián, es el siguiente:

- Mi parte te la cedo, te la puedes quedar.

Esta traducción ha sido rechazada por la parte acusada y su defensa por no corresponder realmente a lo que aparece en la grabación:

- Lo mío te lo cedo, te lo puedes quedar.

Lo que cambia entre los dos enunciados es parte por mio, un detalle aparentemente sin importancia, pero con serias repercusiones jurídicas y judiciales. Si uno dice lo mío estaría hablando de una unidad indivisible, pero si habla de una parte estaría implicando a los otros individuos que tienen las otras partes de loque fuera. Son esas otras partes precisamente las que interesan al Ministerio Fiscal y al juez, empeñados en juzgar a la banda completa y no solo a uno de sus integrantes, cogido con las manos en la masa.

Sin embargo, este celo por la literalidad no siempre surte los efectos oportunos, ya que puede desembocar en construcciones lingüísticas de difícil comprensión, como en este caso, recogido tal y como aparece aquí:

N.- ¿Porque no?

T.- (Ininteligible)

N.- No, no.

T.- ¿De qué te ríes?

N.- No, no, tú me lo mandas por correo, que no, que no...

T.- Que no te voy a partir las piernas...

N.- Que no, pero tú (ininteligible) el tema, que asco de verdad eh...

T.- Que asco dice, ¿pero qué dices? Si te estoy diciendo que no te voy a partir las piernas, ¿De

qué tienes miedo?

N.- Bah, de nada. 
Si nos paramos a observar este fragmento, descontextualizado y sin la proporción de datos extralingüísticos, la interpretación es complicada. De hecho, no es preceptivo que la policía judicial presente una traducción literal de todo el material de escucha, sino parte de él o incluso un resumen incriminatorio, tal y como lo establece la sentencia n ${ }^{\circ} 307 / 2016$ del 13 de abril de 2016 ( $N^{o}$ del Cendoj: 28079120012016100365), relativa a la traducción e interpretación íntegra de escuchas telefónicas en "lenguas africanas", relativas a un delito contra la salud pública.

(...) No se asume el criterio de la Audiencia de exigir como requisito previo para que puedan ser escuchadas y traducidas en la vista oral del juicio que las grabaciones telefónicas consten literal e íntegramente traducidas por escrito en la causa. Es suficiente que se cumplimente el sistema habitual de transcribir los resúmenes de los apartados incriminatorios relevantes contra los acusados, quienes en la vista oral del juicio podrán interesar que se escuchen y traduzcan todos los que pudieran relacionarse con el ejercicio de su derecho de defensa, posibilidad que también pudieron ejercitar en la fase sumarial. Criterios jurisprudenciales de esta Sala sobre la materia. Su inobservancia por el Tribunal sentenciador en el presente caso.

Es bien sabido, que en causas como la anterior, motivada por la condena a una banda traficante de estupefacientes, las escuchas telefónicas no son más, en ocasiones, queun indicio incriminatorio más, entre otras pruebas materiales. Así lo establece, por ejemplo, la STC n ${ }^{\circ} 70 / 2007$ de 16 de abril, que, entre otros extremos, dice:

La sentencia que le condena, no sólo, ni principalmente se basaba en las escuchas telefónicas, pues el descubrimiento de la nave donde se encontraba la droga o se produce por las escuchas telefónicas, sino, de forma paralela, también por los seguimientos policiales a los que eran sometidos los sospechosos, seguimientos que no aparecen dependientes de aquéllas. Por otro lado, los sospechosos ya lo eran antes y con independencia de las mismas, y el descubrimiento de las operaciones de entrega y aprehensión de la droga tiene lugar a causa precisamente de la vigilancia policial a que la nave fue sometida. Por tanto existen otras pruebas de cargo independientes de las escuchas telefónicas.

Aun así, como en el ejemplo sobre lo mío y mi parte citados en este trabajo, la implicación de otras personas en el acto delictivo, más allá de los que se cogieran con la mano en la mesa, requiere un rigor en las grabaciones, en la interpretación, transcripción y comentario, y más aún si son lo único de que dispone el juez. Sin embargo, caso muy distinto es el de la persecución del radicalismo y del terrorismo en que la prevención necesita más garantías todavía que el caso anterior porque no se espera a la ejecución efectiva del acto. En el caso del tráfico de estupefacientes, a los implicados les apresa una vez consumado el acto, pero en el caso de la delincuencia violenta, las ideas, los indicios y demás pruebas se evalúan en base discursiva, previamente al acto, por lo que se requiere más rigor, más conocimiento enciclopédico y extratexual de la materia, y por lo tanto más precisión. Ejemplo de ello es la discordia entre los traductores italianos y los traductores españoles, con respecto a uno de los presuntos implicados en el 11-M, El Egipcio:

El tribunal presidido por Javier Gómez Bermúdez las consideró "claramente equívocas". "Se presentaron bajo titulares de que Rabei había reconocido ser el cerebro del atentado. Cuando los intérpretes españoles escucharon directamente las grabaciones y las tradujeron del árabe constataron que lo que la policía italiana decía que había dicho no era eso. Las frases más importantes y auto imputaciones no existían", evoca Zulueta. "Se habló mucho en el juicio de su extremismo religioso como un indicio de su participación en los hechos. Se habló incluso de una mancha que tenía en la frente de tanto rezar y que lucen millones de musulmanes. Fue una situación muy tensa. Su cara salía todos los días en la prensa como el autor del mayor sufrimiento que ha padecido este país por un atentado. Resultó muy duro" ${ }^{3}$. 
Para concluir, estas líneas dan testimonio de hasta dónde puede llegar la praxis del intérprete de las interceptaciones telefónicas. Una misión, ésta, de mucha transcendencia sobre por una parte la seguridad y el bienestar de la sociedad, y por otra, sobre las garantías judiciales de equidad y universalidad de las que deben gozar los ciudadanos y residentes en territorio español o bajo su jurisdicción judicial. La competencia en interpretación, transcripción y traducción es, en esta especialidad judicial, una necesidad absoluta no solo para asegurar las garantías judiciales de las personas, sino también por su alto coste económico y personal. Echar a perder horas y horas de trabajo de otras personas, así como recursos económicos comunes por fallos indebidos o falta de formación del intérprete es algo que debe tenerse en cuenta en la selección de este personal. Por las mismas razones, no estaría de más organizar cursos de formación para ellos y, sobretodo, elaborar un protocolo de actuación que debe fijar con precisión el procedimiento de actuación de los intérpretes en el ámbito judicial de las interceptaciones telefónicas.

Por la misma razón debe integrarse al intérprete en el equipo de trabajo como uno más, sin menoscabo de los controles internos y supervisión de los cuales ni los mismos agentes policiales pueden evadirse. Esto puede conseguirse mediante el desplazamiento de la sumisión del intérprete a su policíacontrolador, a las leyes, normas y reglamentos que regulen su trabajo e intervención.

Se observado igualmente que el trabajo del intérprete policial necesita unas destrezas específicas que van más allá las distintas modalidades regulares en la formación del graduado en Traducción e Interpretación. Los conocimientos culturales universales son comunes para todos los intérpretes, pero en el caso del profesional, objeto de la presente investigación, el conocimiento de las subculturas, del uso sui generis que se hace de la lengua común, de la aprehensión general de su labor y su repercusión sobre la seguridad ciudadana y sobre la consagración de la justicia, además de rasgos de personalidad como la autonomía en la toma de decisiones, la conciencia de sí mismo y de la independencia de su especialidady de su cometido en las investigaciones en que participa. Todo ello sin menoscabo de sus aptitudes a trabajar en equipo y de colaborar con los distintos miembros de los distintos grupos implicados, hasta llegar al mismo juez.

El corpus observado, constituido por datos lingüístico-culturales específicos sacadas de la experiencia cotidiana de intérpretes y peritos en el ámbito judicial, refleja que el oficio del intérprete policial debe tener una formación específica por cuanto implica simultáneamente varios saberes, incluido el modus operandi del mundo de la delincuencia. Esto es lo que permitido, como se ha visto arriba, al intérprete resolver que el "pan redondo" es una rotonda en una carretera, y que "el hombre de la guitarra" es el Tío Pepe. Los conocimientos, propios del área de la lingüística, como la pragmática y la semiótica son las que han permitido, como en el caso anterior, y permiten dilucidar las diferencias significativas entre los que dice y lo que se quiere decir.

\section{BIBLIOGRAFÍA}

Casabianca Zuleta, P. (2015): Las intervenciones telefónicas en el sistema penal (Tesis Doctoral). Salamanca, Universidad de Salamanca.

Cavero Forradellas, G. (S./F.): "La nueva regulación de las intervenciones telefónicas en la ley de enjuiciamiento criminal, en https://www.fiscal.es/fiscal/PA_WebApp_SGNTJ_NFIS/descarga/Ponencia\%20Cavero\%20F orradellas, \%20Gerardo.pdf?idFile=38380825-2079-4304-af21-40d9010e0ae9 [21/10/2018].

Cayón Sáez, L. J. (2013). Sobre la interpretación para los servicios públicos en los ámbitos judicial y policial en la provincia de Málaga: estudio de caso. Tesis doctoral. Málaga, Universidad de Málaga.

González Rodríguez, M. J. (2015). "Interpretación para escuchas telefónicas: de la experiencia profesional a su didáctica", en Nuevos horizontes en los Estudios de Traducción e Interpretación (Trabajos completos). Geneva, Editions'Tradulex, pp. 29 - 38. 
La precisión conceptual y terminológica en el ámbito policial y judicial: traducción y transcripción ...

González Rodríguez, M. J. (2015). «Interpretar escuchas telefónicas en ámbito judicial: análisis descriptivo y metodología operacional», en TRANS, Revista de Traductología. Málaga, Universidad de Málaga Servicio de Publicaciones, vol. 19, pp. 109 - 129.

Hale, S. B. (2010). La interpretación comunitaria, la interpretación en los sectores jurídico, sanitario y social. Granada, Comares.

Luncan, I. A. (2014). La interpretación en los servicios públicos: la interpretación policial en España (Trabajo Fin de Grado). Castellón, Universitat Jaume I.

Notario Dongil, A. (2013). Transcripción y traducción forense: características y su uso durante el proceso, el proceso judicial, propuesta de criterios comunes. Trabajo Fin de Máster. Alcalá de Henares, Universidad de Alcalá.

Ortega Arjonilla, E. (2009): “La traducción judicial (francés-español / español-francés) a examen: conceptualización, práctica profesional y aplicaciones didácticas”, en Revista electrónica de didáctica de la traducción y la interpretación, $\mathrm{N}^{\circ}$. 2, págs. 53-75.

Ortega Arjonilla, E. (2016): "De barreras culturales en la traducción jurídica y administrativa del francés al español: Aplicaciones al ámbito de la extranjería", en EURRUTIA CAVERO, M. M., El lenguaje jurídico y administrativo en el ámbito de la extranjería Estudio multilingüe e implicaciones socioculturales. Suiza: Peter Lang.

Pascual Brotons, N. (2015). La intervención del traductor-intérprete en la interceptación de telecomunicaciones en el ámbito policial español: situación actual y propuestas de mejora. Trabajo Fin de Grado. Alicante, Universidad de Alicante.

Pegenaute, L. (2009). "Traducción, globalización y terrorismo internacional: una lectura a través de la prensa española", en Traduçaoem revista, 7: pp. 01-09.

Ron Romero, J. (2011): "Derecho al secreto de las comunicaciones telefónicas. Un reto para la buena administración" en Anuario da Facultade de Dereito da Universidade da Coruña. La Coruña, Universidad de La Coruña. págs. 101-126. 